\title{
SHAPING SENIOR LEADER OFFICER TALENT: HOW PERSONNEL MANAGEMENT DECISIONS AND ATTRITION IMPACT THE FLOW OF ARMY OFFICER TALENT THROUGHOUT THE OFFICER CAREER MODEL
}

\author{
Matthew F. Dabkowski \\ Samuel H. Huddleston \\ Paul Kucik \\ United States Military Academy \\ Department of Systems Engineering \\ West Point, N.Y. 10996
}

\author{
David Lyle \\ United States Military Academy \\ Department of Social Sciences \\ West Point, N.Y. 10996
}

\begin{abstract}
Army Officers play a critical role in our nation's security strategy. Throughout a career of service, officers develop talents through a unique and rare set of experiences, education, and formal training. The demand by corporations for these talents, coupled with a distinct feature of the Officer Career Model, limited lateral entry, create significant retention challenges for the U.S. Army. Understanding how personnel policies, resources, and organizational decisions affect the flow of officer talent through the Officer Career Model is a first step in addressing these retention challenges. This analysis employs discrete event simulation to quantify the probable impacts of attrition on the distribution of talent available for service across the Army's officer ranks.
\end{abstract}

\section{INTRODUCTION}

Our nation requires a talented Army officer corps and for good reason. Army officers implement our national security policies, direct our national defense establishment, and lead our sons and daughters into combat. It is therefore vital that the Army acquires, develops, employs, and retains the best officer talent that it can. The unique nature of the military, however, limits lateral entry to mid-career and senior-level billets. Unlike industry, which can poach mid-career and senior-level leaders from other firms, the Army must build its mid-career and senior leaders out of the lieutenants that it commissions each year. Limited lateral entry, therefore, places a premium on the Army developing and retaining the officer talent it needs in its mid and senior level positions. Officer retention data shows that the Army has been hemorrhaging officer talent for much of the past quarter century.

As the nation shifted from the industrial age to the information age in the mid 1980s, the Army experienced a decline in officer retention. Prior to the mid1980s, the Army could expect 60 percent of its officers to remain on active duty through eight years of service. Since the mid-1980s, approximately 40 percent of officers have continued past eight years of service. Although likely the result of several factors, one of the more concerning is the overall increased demand for the talent associated with Army officers. Robust leadership opportunities at a relatively young age coupled with generous educational and training opportunities make Army officers an attractive candidate to industry. Figure 1 below shows how a quarter century of low officer retention have resulted in officer inventory and requirement imbalances. 


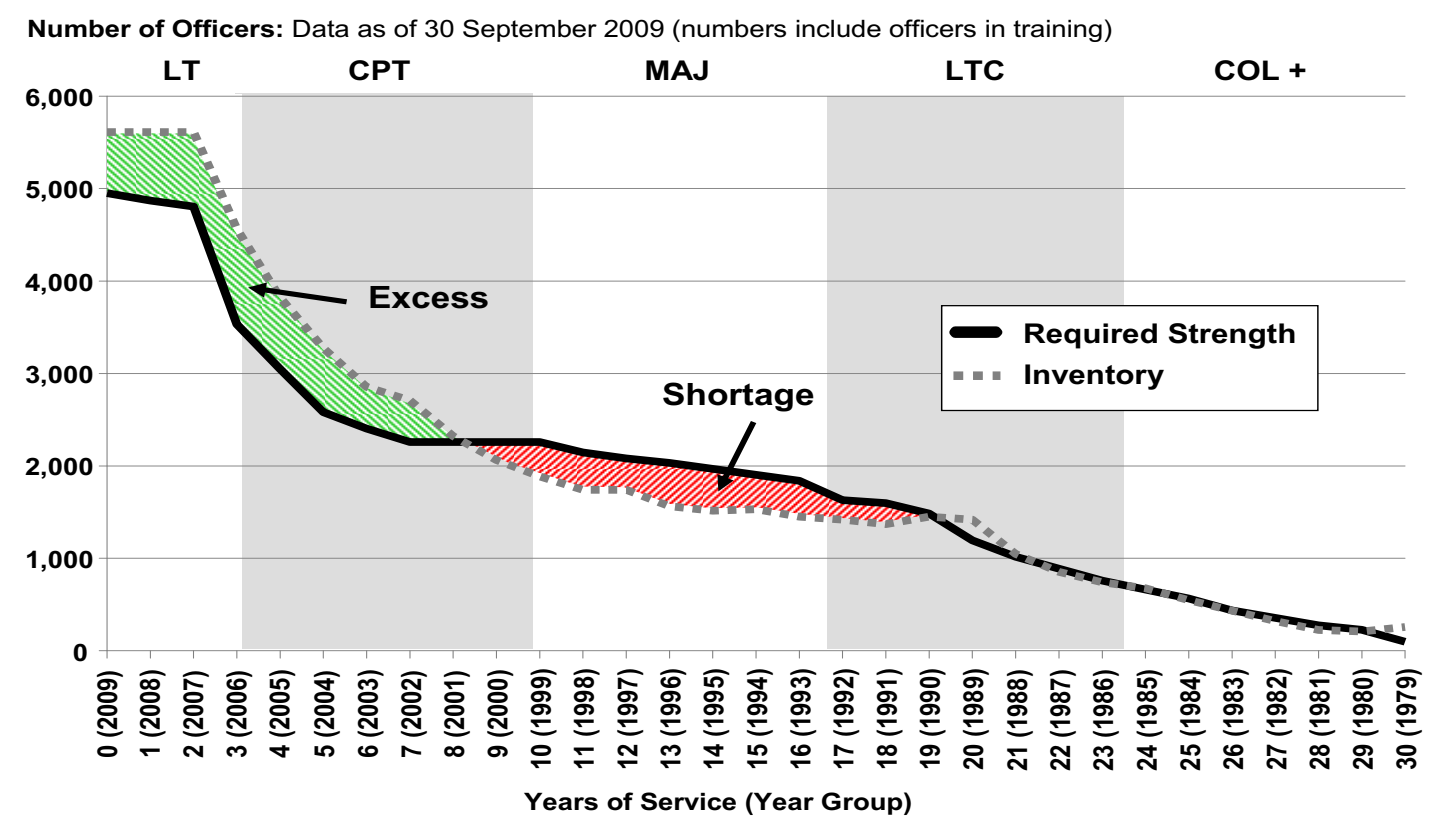

Figure 1: Officer Requirements and Inventory Imbalances

Figure 1 paints a concerning picture of the current state of the Army Officer Corps: there are more junior officers than the Army can employ, and the Army is critically short mid-career officers. Beyond the sheer number imbalance, however, is the question of talent. Is the Army retaining the talent it needs across all of its ranks - through General Officer? Although an imperfect answer to this question, evidence in Figure 2 suggests that it is not. Promotion rates to Colonel (panel C) show that the Army would prefer to retain more officers from the top of the West Point class. Yet more than 70 percent of officers have left by 19 years of service (panel A), more than 80 percent have left by 22 years of service (panel B), and retention rates are relatively uniform across the order of merit quartiles.

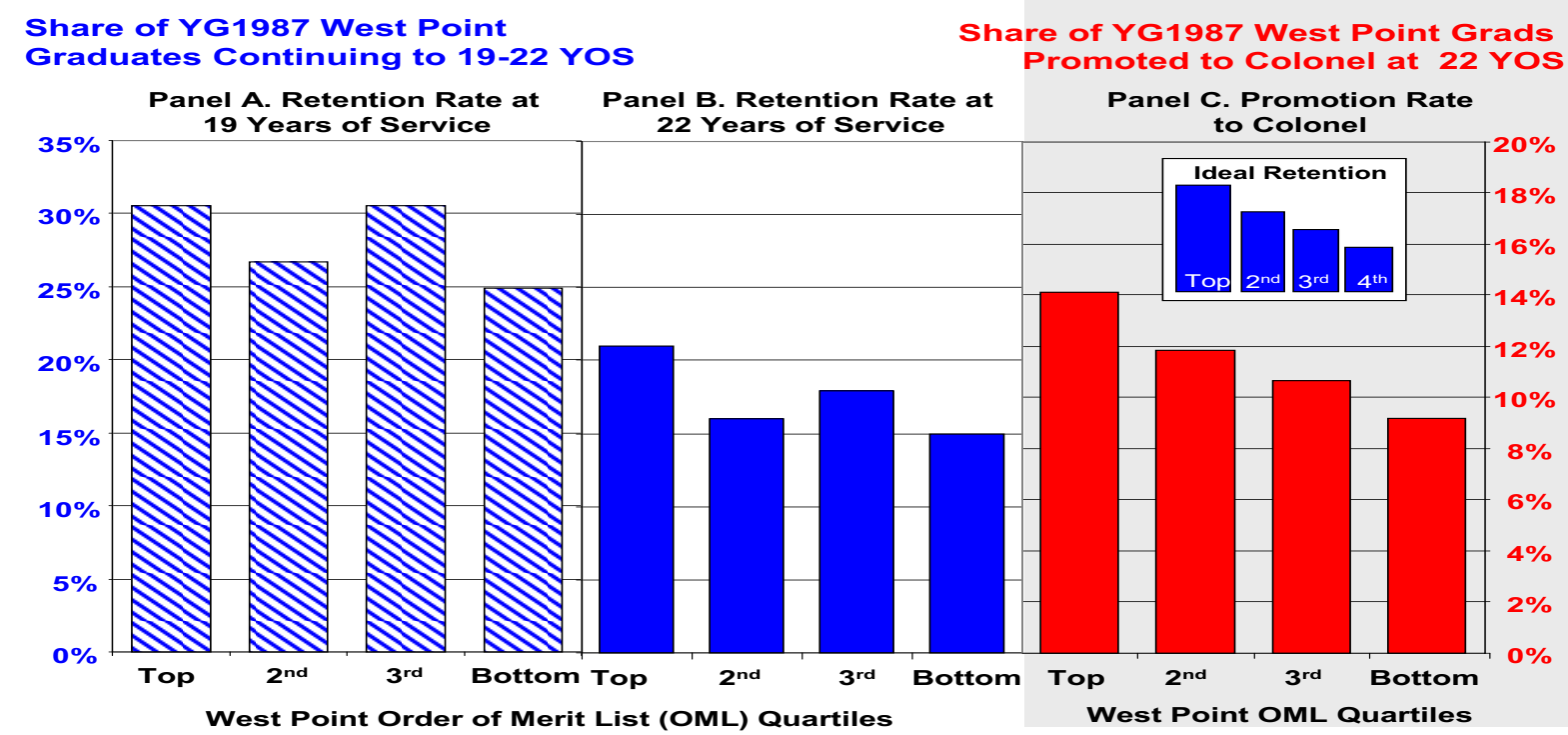

Figure 2: Retention \& Promotion rates of Year Group 1987 officers by performance at West Point 
Data from Figure 2 suggest the Army must seek ways to retain more of its top-flight talent through its senior ranks. To better understand the implications of talent, we begin by providing a brief definition of talent and some background on the unique dimensions of the Officer Career Model (OCM). We then develop simulation models that demonstrate the effects of various personnel policies on the flow of talent throughout the OCM. The simulation in this paper focuses on a single dimension of talent and a single career path. Future work will expand the model to multiple dimensions of talent across multiple career paths.

\section{BACKGROUND}

Our definition of talent draws heavily on a recent Strategic Studies Institute Monograph Series entitled, "Talent: Implications for a U.S. Army Officer Corps Strategy" (Wardynski, Lyle, and Colarusso 2010). Talent is something that everyone has and its dimensions are limitless. Talent comprises everything that contributes to an individual's productivity. In the broadest sense, this spans the food we eat, how tall we are, how well we see, our intellectual acuity, our motivations, attitudes - essentially everything that makes us productive. Because talent is virtually limitless in its dimension, it is not possible to say that one person is more talented than another, unless we identify a single dimension for comparison. Allyson may be more talented at playing the piano than Andrew, but Andrew is more talented at basketball.

For ease of discussion, these countless attributes are binned into three key dimensions: skills, knowledge, and behavior. At any point in time, skills are the native abilities, intelligences, preferences, and backgrounds that an individual possesses. Knowledge involves the education, training, and experience that build on the initial set of skills. Behaviors are the values, ethics, motivations, and attitudes that shape how skills and knowledge are projected to achieve outcomes. Although distinct, these three dimensions have a great deal of overlap.

We represent this non-linear view of talent graphically with a standard bell-shaped distribution. Figure 3 represents an individual's distribution of talent. Using this three dimension taxonomy, this person has a broad skill distribution (many skills), a deep knowledge set (expertise), and an average breadthdepth behavioral distribution. Loosely speaking, the intersection of these three distributions comprises the individual's overall talent distribution. Each person has a unique talent distribution and this distribution evolves over time as skills, knowledge, and behaviors develop throughout life.

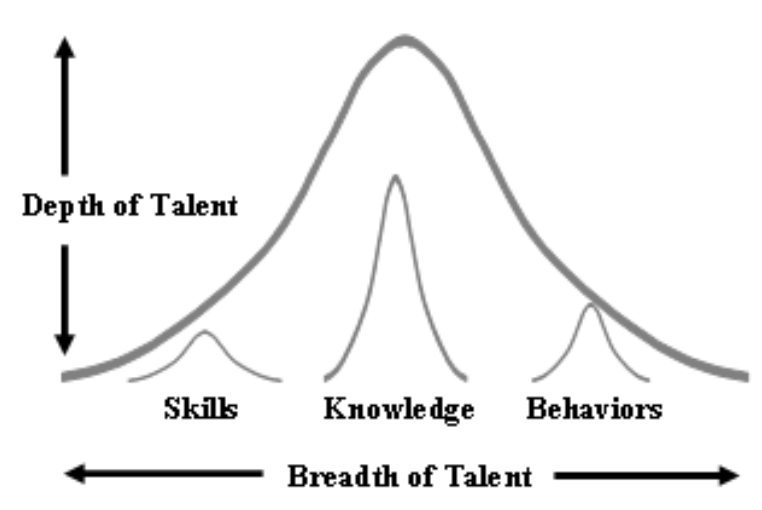

Figure 3: Individual Talent Distribution

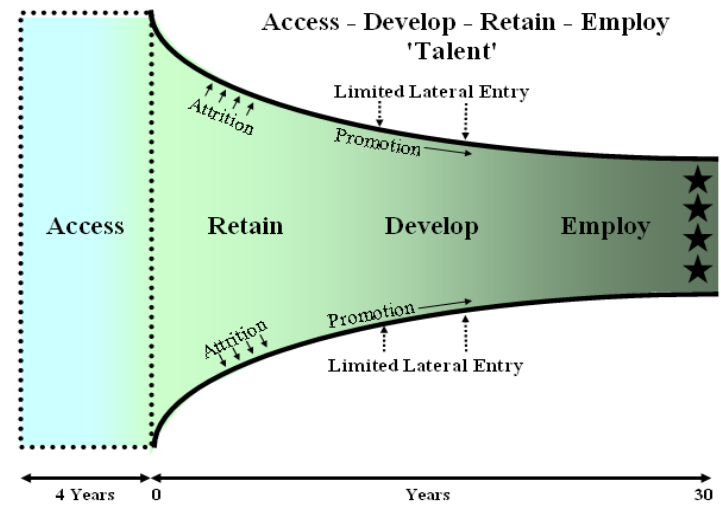

Figure 4: Army OCM

Understanding talent in this context has important implications for how the Army manages the four components of its OCM: accessing, retaining, developing, and employing officer talent. Figure 4 depicts this model graphically and highlights several unique characteristics of the OCM that dramatically impact the flow of officer talent. As described earlier, one of the most distinctive features of the Army's OCM is that the Army limits lateral entry into its mid and senior level officer ranks. The unique nature of military service suggests that the Army is not apt to change this assumption anytime soon. Since the Army cannot 
go out and purchase mid and senior level officer talent, it must retain the officer talent it needs throughout the OCM. Unlike the enlisted ranks, which have well-defined enlistment periods, officers serving past their initial Active Duty Service Obligations (ADSOs) are free to leave the Army at any point in time. Most officers who depart active duty leave somewhere between the completion of their ADSO and ten years in service. Officers who serve past ten years typically remain on active duty through 20 years of service, when they become eligible for generous retirement benefits. All officers who do not reach the rank of General must retire by 30 years of service.

As shown in both Figures 1 and 4, the Army does not require all officers to stay on active duty through a 30 year career. In fact, throughout the 1980s and the early 1990s, the Army only promoted roughly 70 percent of its officers to the rank of Major and 60 percent of its officers to the rank of Lieutenant Colonel. This high degree of selectivity allowed the Army to shape its senior-leader talent pool by screening, vetting, and culling its officer talent. Figure 5 demonstrates how this process can improve the overall pool of talent. For example, the distribution of talent with mean $\mu_{1}$ represents the applicants of officer candidates. By being selective in offering scholarships, the Army can achieve a distribution with a higher mean, $\mu_{2}$. By further vetting these candidates against each other and time honored standards, a refined merit listing emerges. Culling or eliminating the lower tail of the distribution results in a new distribution with an even higher mean, $\mu_{3}$. Such a process of screening, vetting, and culling allows the Army to continually improve its talent pool in aggregate as officers progress through the OCM.

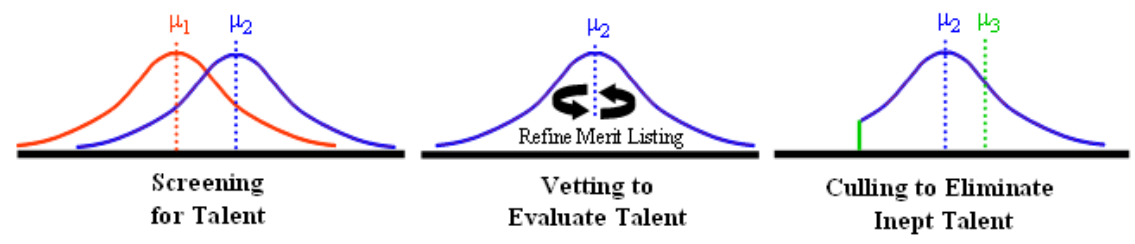

Figure 5: Screening, Vetting, and Culling for Talent

Low retention that caused the shortage in Majors (Figure 1) has forced the Army to increase promotion rates above 90 percent through the rank of Lieutenant Colonel over much of the last decade. Low retention also forced the Army to begin over-accessing Lieutenants to make up for shortages in the midcareer ranks. Together these policies have important implications for how talent is currently flowing through the OCM. Next, we turn to simulation to better understand the flow of officer talent.

\section{SIMULATION MODEL}

While the notion of measuring officer talent is entirely conceptual at this point, we do not need actual measurements to generate insights or assess the likely impacts of various policies on it. Specifically, by assuming a reasonable underlying probability distribution for officer talent, using historical continuation rates, and applying hypothesized promotion rules, we can quantify (in relative terms) how the Army's ability to recruit and retain its officers affects the talent of its leadership.

Now, suppose we are interested in calculating the expected talent of the Lieutenant with the $100^{\text {th }}$ highest talent in a given cohort if (a) officer talent follows a normal distribution and (b) we are asking this question immediately following commissioning (such that neither attrition nor promotion is possible). Following standardization, this is equivalent to finding $E\left[Z_{(r)}\right]$, which requires solving $E\left[Z_{(r)}\right]=\frac{n !}{(r-1) !(n-r) !} \int_{-\infty}^{\infty} z(\Phi(z))^{r-1}(1-\Phi(z))^{n-r} \phi(z) d z$ where $Z$ represents officer talent, $\Phi(z)=\int_{-\infty}^{z} \phi(t) d t$, $\phi(z)=\frac{1}{\sqrt{2 \pi}} e^{-z^{2} / 2}, n$ is the total number of officers accessed in the Lieutenant's cohort, and $r$ equals 100 (Ahsanullah and Nevzorov 2005). Unfortunately, the calculation of $\Phi(z)$ requires numerical integration, and, therefore, $E\left[Z_{(r)}\right]$ has "explicit expressions only in some special situations for small sample sizes" (Ahsanullah and Nevzorov 2005, pg. 121). Moreover, the number of Army officers in a given cohort rou- 
tinely exceeds 5000. Thus, neither explicit calculations nor tabulated values will allow us to calculate the expected talent of the Lieutenant with the $100^{\text {th }}$ highest talent in a given cohort. Of course, the situation does not improve once the continuation rate enters the picture; another approach is needed - simulation.

\subsection{Model Assumptions and Structure}

First, for the purpose of this simple simulation model, we assert that talent exists (in one dimension) and that we can measure it. We also assume that talent is a trait that officers inherently own and that it, like many natural traits such as height, weight, and intelligence, is normally distributed in a cohort's population year group.

In order to provide some context and without loss of generality, we assume a mean talent score of 50 with a standard deviation of 13 in order to distribute the talent scores between 0 and 100 (outliers above 100 and below 0 are possible but unlikely). This means that a person with a talent score of 63 is one standard deviation above the mean and is at about the 84 th percentile. Less than $2.5 \%$ of officers will have a talent score above 76 (two standard deviations above the mean). The talent scores themselves are not tied to a defined level of performance in the real world but rather serve as a way to "keep score" on how various states of the world and policies affect the talent pool available at the senior levels of the Army.

Second, we assume that an officer resigns due to his experience variable. Officers have an opportunity to "off-ramp" throughout their careers. In this simulation, we give officers the opportunity to resign once at each rank, and we ensure that the same percentage of officers resign at each rank as did with an actual cohort - in this case Cohort Year Group 1986 (YG86). At each rank, an officer's experience variable is drawn from a uniform distribution. The officer with the worst experience (i.e. the smallest random variate) is the first to depart, and attrition continues until the number of officers who have resigned at that rank matches the historical departure rate for the cohort.

Finally, we assume that the promotion boards perform flawlessly. Specifically, they can perfectly assess a person's talent score and will always promote the most qualified personnel available to the next rank. Currently, officers who submit paperwork indicating their desire to separate from active duty are not eligible for promotion. Thus, at each rank, the cohort year group is trimmed by attrition, resulting in a smaller cohort that appears before the board. The promotion board in the simulation model then promotes the most qualified personnel remaining in the cohort year group. Moreover, the number of officers promoted to the next rank is equal to the historical number of officers promoted for the cohort.

\subsection{Model Scenarios}

We begin this analysis by proposing three scenarios that reflect possible states of the world. We then simulate the flow of YG86 through these scenarios to gauge their impact on the officer talent pool available at the senior ranks of the Army. Each of these scenarios is described in depth below.

\subsubsection{Scenario 1: No Attrition Model}

The No-Attrition Model is a simplification of the model described above in that no attrition takes place. Rather, the only way an officer departs is if he is not selected by the promotion board for advancement to the next higher grade. This is obviously an unrealistic scenario, but is considered here because it illustrates a mental paradigm most people carry with them about the effect of promotion boards. The assumption is that because the promotion boards are promoting only the best available in each round, there is a steady increase in the average talent level at each grade. While that may be the case when other factors such as experience and development are considered, this scenario shows that when attrition is considered the raw, natural talent available at each grade does not necessarily increase due to the effect of promotion boards unless the no-attrition assumption is made. This example is provided as a counter-point and is graphed in the left-most panel of Figure 6. (Note: While Figure 6 displays the output of the No At- 
trition Model generated by Monte Carlo simulation, very good, computationally efficient approximations are possible using order statistics. See the appendix for a discussion of these techniques.)

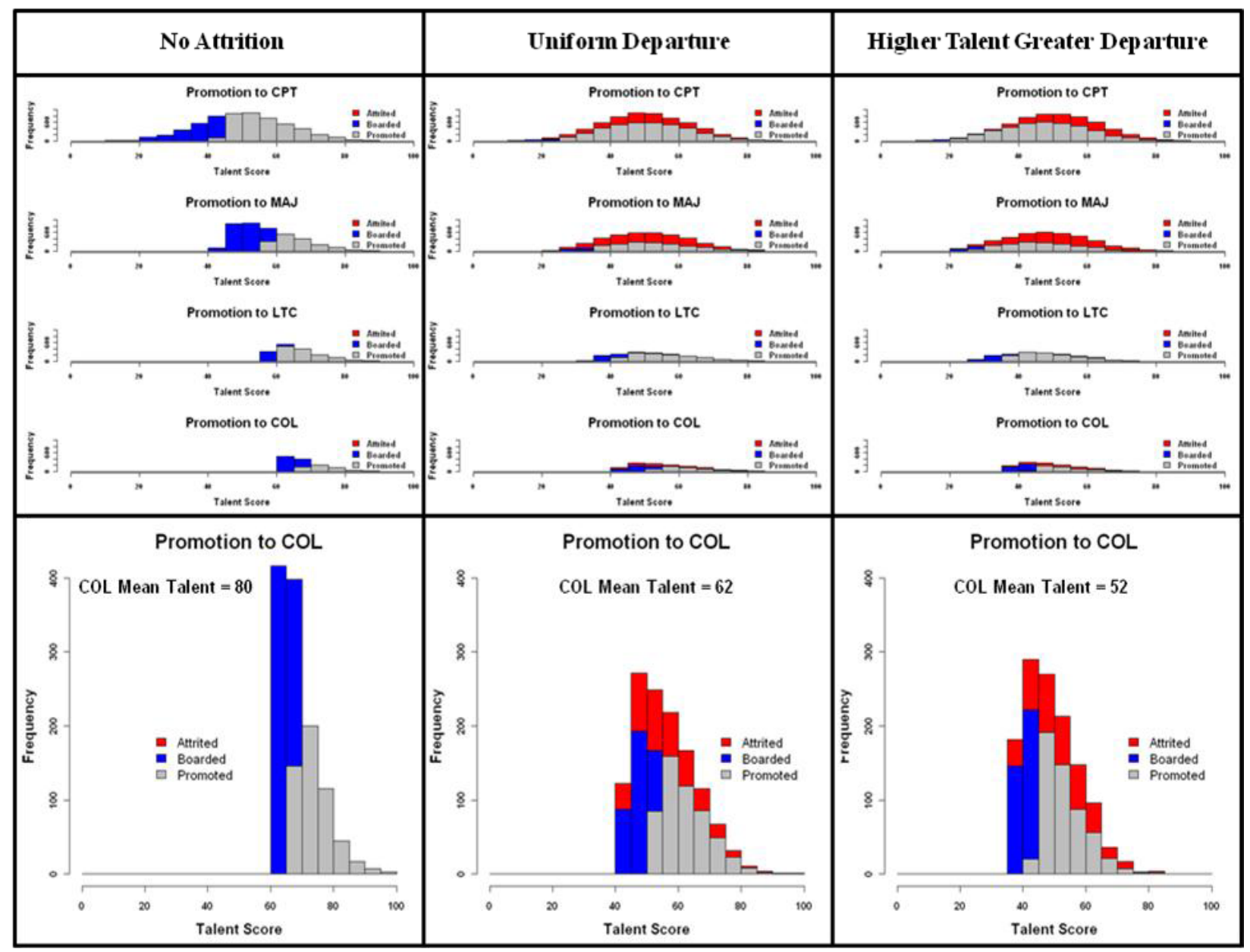

Figure 6: Simulation results of the cascading effects of attrition and promotion boards on cohort talent as they progress through an Army career, beginning with promotion to Captain at the top and finishing with promotion to Colonel at the bottom. These scenarios use actual attrition and promotion numbers for the 1986 Cohort Year Group. The results are graphed under three scenarios: higher talent greater departure, uniform attrition, and no attrition. The bottom panels represent expanded (rescaled) versions of the promotion board to Colonel for ease of viewing. Red histograms represent the original cohort at the previous rank for each board (the red area designates those officers who resigned before being observed by the promotion board); blue represents the boarded cohort (those officers considered for promotion) and gray histograms reflect the officers selected for promotion to the indicated grade.

\subsubsection{Scenario 2: Talent Is Not Associated with Departure (Uniform Departure Model)}

The Uniform Departure Model assumes that officers make a decision about departing the Army independent of their talent. In this scenario, there is no opportunity cost for officers who are exceptionally talented. Each officer makes the decision to stay or leave based upon the "experience variable" drawn from a uniform distribution at each rank. This means that every officer is equally likely to depart at each rank. The promotion boards continue to promote the best officers presented to them in each round of boards, but, because attrition now begins to take effect, the boards are now promoting "the best of what's left." 
This scenario represents what is probably a very conservative estimate of the negative effect of attrition on the talent pool and is graphed in the center panel of Figure 6.

\subsubsection{Scenario 3: Higher Talent Individuals Are More Likely To Depart (Higher Talent Greater Departure Model)}

A recent Fortune Magazine cover article documents "why companies like Wal-Mart, PepsiCo, and GE are recruiting the military's elite" to fill their junior executive leader development programs (O'Keefe 2010). Scenario 3 is designed to mimic the opportunity cost scenario often placed in front of the Army's best officers. In this scenario, officers have a "propensity" to depart that corresponds with their talent score. This propensity reflects the opportunity costs presented by a business market eager to "recruit the military elite."

In this model, the propensity to depart ranges from 0 to 1 in concert with the talent score between 0 and 100. At each rank, an officer once again draws a uniformly distributed "experience variable" based upon their Army experience at that rank. However, in this scenario, the officer evaluates the delta between their propensity to depart (or opportunity cost based upon talent) and their Army experience. A random draw of a fantastic experience in the Army can overwhelm the propensity variable of even exceptionally talented officers, but the high-talent officers have a higher probability of departure in each round than those with lower talent. This scenario represents what is probably a very aggressive estimate for the negative effect of attrition on the talent pool but reflects the intent of the business market as described in recent magazine articles. This scenario is graphed in the right panel of Figure 6.

\section{SIMULATION MODEL RESULTS AND INSIGHTS}

Analysis of Figure 6 yields some important insights. First, it is obvious that attrition has a very heavy impact on the talent available at the highest ranks of the Army, unless one assumes that attrition does not take place. In the No Attrition Model, the average Colonel is truly exceptional (because about 9\% of YG86 was promoted to Colonel, this population represents the top 9\% of officers). However, the amount of attrition YG86 experiences seriously impacts the talent level, even under the very conservative assumptions of the Uniform Departure Model.

Figure 6 also illustrates that the opportunity cost presented by the business market can have a very powerful effect. In the Uniform Model, the average talent is well above average. With an average score of 62, the average Colonel is roughly one standard deviation above the mean and at about the 82nd percentile. The worst Colonel in the cohort under this scenario is the definition for average, with a talent score of 50. However, under the Higher Talent Greater Departure scenario, the average Colonel is only slightly above average (talent score of 52) and the worst Colonel promoted is at the 29th percentile (talent score 43).

Further use of the simulation model allows us to directly compare the impact attrition and promotion boards at each rank have on the resulting talent pool. Using the Higher Talent Greater Departure scenario, we simulated 100 replications of YG86, and we output the average mean, maximum, median, and minimum talent of the cohort before and immediately after the Colonel promotion board. Given in Table 1 below, the effect of late career attrition on officer talent is striking. Specifically, when we simulate the cohort using historical attrition rates at each rank, we notice that the promotion board for Colonel has little impact on the metrics. On the other hand, if the Army adopted an incentive structure such that virtually no attrition occurred at the rank of Lieutenant Colonel, then the Army reaps marked improvements in all metrics. To implement such an incentive structure, the Army could announce the selection results for Colonel, before Lieutenant Colonels become eligible for retirement; each officer selected for Colonel would have very strong incentives to continue service for at least three years beyond his or her promotion date to lock in considerably higher retirement pay for the remainder of his or her life. The effect of this is labeled the attrition effect; it represents the marginal improvement in talent if the Army had no attrition at that rank. In Table 1 below, the promotion board provides the effect in the first column, and the second 
column records the effects that could be achieved in addition to the board effect. Thus, the Colonels have a mean talent score of 52.76 (an improvement of 4.79 over the boarded cohort) but that talent score could have been 56.91 if there had been no attrition (an additional improvement of 4.15).

Table 1: The Attrition Effect Under the Higher Talent Greater Departure Scenario

\begin{tabular}{lcc}
\hline \multicolumn{1}{c}{ Metric } & Historical Attrition & No LTC Attrition \\
\hline Mean LTC Talent After Attrition & 47.97 & 48.95 \\
Mean COL Talent & 52.76 & 56.91 \\
Improvement in the Mean & 4.79 & 4.15 \\
\hline Maximum LTC Talent After Attrition & 78.88 & 81.71 \\
Maximum COL Talent & 78.88 & 81.71 \\
Improvement in the Maximum & 0.00 & 2.83 \\
\hline Median LTC Talent After Attrition & 46.66 & 47.69 \\
Median COL Talent & 51.32 & 55.52 \\
Improvement in the Median & 4.66 & 4.20 \\
\hline Minimum LTC Talent After Attrition & 36.64 & 36.64 \\
Minimum COL Talent & 44.51 & 49.46 \\
Improvement the Minimum & 7.87 & 4.95 \\
\hline
\end{tabular}

The truth of the matter in the Army today almost surely lies somewhere between the very negative picture presented in the Higher Talent Greater Departure scenario and the very conservative Uniform Departure scenario. There is no question that corporate America aggressively seeks the most promising officers to fill its ranks and is probably less interested in those officers the Army does not select for promotion. However, the results depicted in Table 1 give us waypoints in developing methods to improve the talent available at the senior levels of the Army.

\section{IMPROVING OFFICER TALENT AT THE SENIOR RANKS}

The simulation models suggest several approaches that the Army could take immediately to improve its available talent at the senior levels for future generations of officers. These include, in order of feasibility, preventing LTC attrition, assessing higher talent, and flipping the attrition profile so that the most talented are the most likely to stay.

\subsection{Intervene at the LTC Level}

One insight that can be gleaned from Table 1 is the powerful effect that the heavy departure of Lieutenant Colonels has on the available talent at the Colonel rank. Attrition for YG86 exceeded 30\% between promotion to Lieutenant Colonel and the board files for the Colonel promotion board. The question is, who were those $30 \%$ ? Unfortunately, regardless of whether those departing officers were the best we had at that rank or whether they reflected a cross-section of talent, we would have promoted many of them as the best available talent had they remained.

Eliminating attrition at the Lieutenant Colonel level before the Colonel board would have a substantial effect on the talent selected for promotion as seen in Table 1. The mean talent score for those selected for promotion would increase by 5 points, moving from a mean of 53 to a mean of 57 under the Higher Talent Greater Departure scenario. That means that the average Colonel moves from the 59th to the 70th percentile. 
Figure 7 below illustrates the resulting shift in the talent pool that would come about if we were to promote (or select for promotion) those officers before they became eligible to retire. The difference between these two graphics represents the opportunity cost to the Army of the late promotion boards we currently hold. The Air Force, as a matter of policy to affect attrition, selects its future Colonels before they become eligible for retirement. Although we may not retain all of the officers we desire to promote, holding an earlier promotion board would provide an incentive for the best officers to remain and allow the Army to determine whether or not the best officers are leaving at this critical juncture.
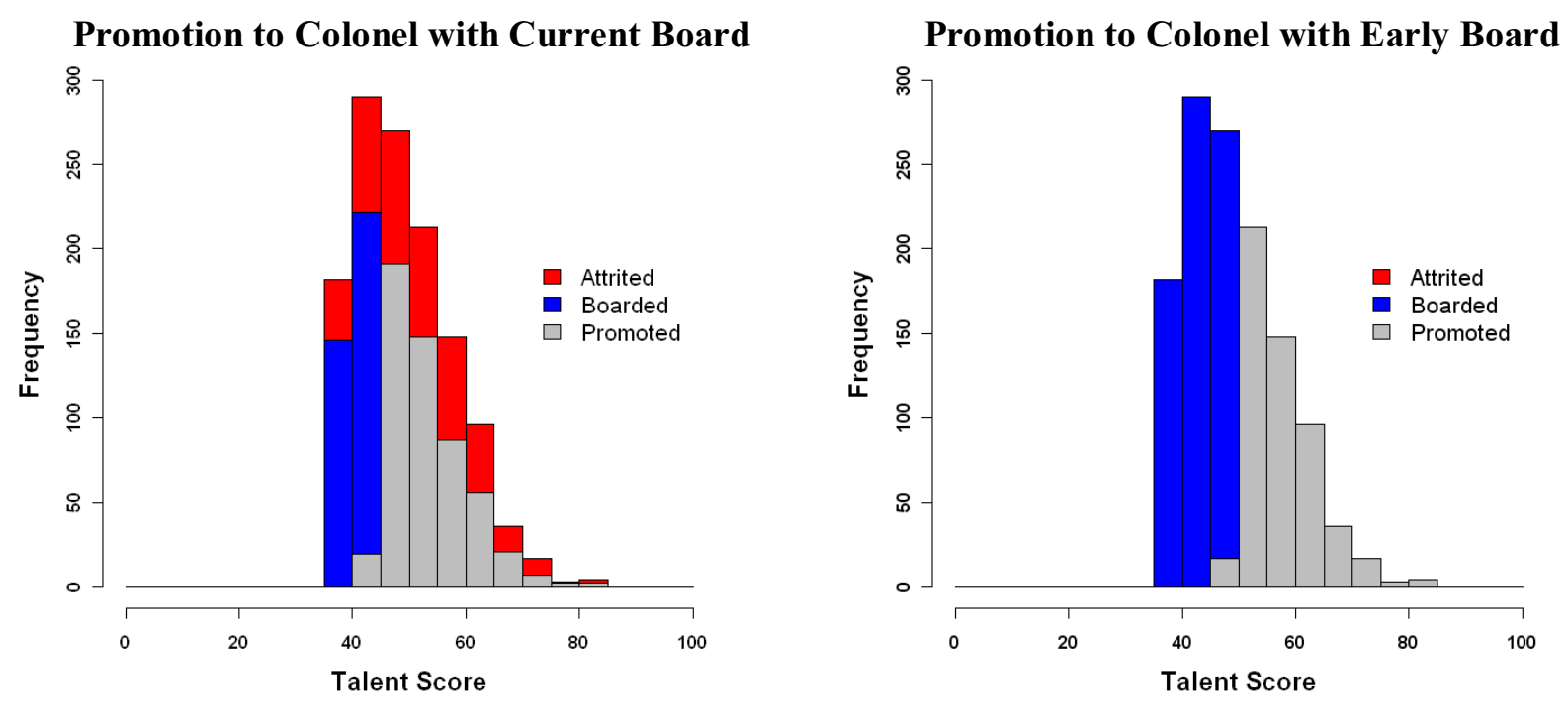

Figure 7: Comparison of the results of the Colonel promotion board under the Higher Talent Greater Departure scenario for the current timeline and a timeline that allows selection for promotion before retirement eligibility. The mean talent score improves by 5 points. The average Colonel selected by the board moves from the 56th percentile to the 70th percentile in this scenario.

\subsection{Modify the Initial Distribution: Access Higher Talent}

While the above option is keeping the best of what you have remaining, an alternative and potentially complementary strategy is to get better people in the first place. One method of implementing such a policy would be to actively screen for talent at accession, while another would be to uniformly pursue more talented officers through widespread incentives and recruiting. An additional (and likely controversial approach) would be to selectively target, access, and retain a small, ultra-talented group. Statistically, these three methods are equivalent to truncating, shifting, and skewing the initial talent distribution, and each method has potential merits for the Army.

\subsection{Flip the Attrition Model: Now the Highest Talent Are the Most Likely to Stay}

The last option might be the least feasible but with the highest payoff: flip the attrition model so that the most talented are the least likely to depart. This would mean aggressively competing with corporate America for the most talented officers. This implies determining why the most competent officers depart (we must first make sure we know who they are) and then developing systems and programs around keeping those specific types of people. This would be an expensive and uncertain undertaking. However, out of all the scenarios discussed, it produces the best result (as one would expect). The marginal improvement of this approach over the Uniform Departure Scenario moves the mean talent score for Colonel from 62 (82nd percentile) to 69 (93rd percentile). 


\section{CONCLUSIONS}

The ultimate question is whether or not the marginal improvement in the average Colonel would be worth the expense moving us between the scenarios presented in this paper. The Army must ultimately determine 1) which of the presented scenarios it is in, 2) which of the scenarios is the minimum acceptable, and 3) whether the benefits of moving from one scenario to the other outweigh the costs. For example, the Higher Talent Greater Departure scenario results in a median Colonel talent score that is actually only slightly higher than that of the Second Lieutenant population, while movement to the Higher Talent Lower Departure results in significant improvements in quality. The cost benefit analysis of the policies required to cause this shift is beyond the scope of this paper. However, this simulation model does provide some important insights on possible approaches the Army could use to improve talent at the senior officer levels. One immediate target of opportunity is a change of policy regarding the timeline of the Colonel promotion board.

One possible limitation of this paper is the use of a single measure for talent. A productive extension of this research might incorporate multiple dimensions of talent. For example, one dimension of talent could be leadership and the second could be technical expertise. While there is likely to be some correlation between the two dimensions, incorporating multiple dimensions would more accurately portray the diverse talents of the officer corps and the needs of the Army.

\section{APPENDICES}

\section{A APPROXIMATING OFFICER POTENTIALS IN THE NO ATTRITION MODEL}

Using the standard convention of order statistics, the ranks, $r$, of a sample are assigned from the smallest to the largest observation such that $X_{1: n} \leq X_{2: n} \leq \ldots \leq X_{r-1: n} \leq X_{r: n} \leq X_{r+1: n} \leq \ldots \leq X_{n: n}$. In his article "Explicit expressions for moments of order statistics," Nadarajah (2008) derived analytically tractable, closed-form expressions for several commonly used distributions, including the normal. While incredibly interesting, the calculation of his result is far from trivial; thus, we used a simpler and sufficient approximation from David (1981). Specifically, it is possible to use the inverse cumulative distribution function (CDF) and its derivatives to estimate the expected value of the $r^{\text {th }}$ largest observation in a sample of $n$ observations according to the relation:

$$
E\left[X_{r: n}\right]=Q_{r}+\frac{p_{r} q_{r}}{2(n+2)} Q_{r}^{\prime \prime}+\frac{p_{r} q_{r}}{(n+2)^{2}}\left[\frac{1}{3}\left(q_{r}-p_{r}\right) Q_{r}^{\prime \prime \prime}+\frac{1}{8} q_{r} p_{r} Q_{r}^{\mathrm{m} \prime \prime}\right]
$$

where $p_{r}=r /(n+1), q_{r}=1-p_{r}$ and $Q_{r}$ represents the inverse CDF of the officer talent probability distribution evaluated at $p_{r}$ (David 1981). In the case of a $N(0,1)$ parent distribution, (1) takes the form:

$$
\begin{aligned}
E\left[X_{r: n}\right] & =\Phi^{-1}\left(p_{r}\right)+\frac{p_{r} q_{r}}{2(n+2)}\left(\frac{\Phi^{-1}\left(p_{r}\right)}{\phi^{2}\left(\Phi^{-1}\left(p_{r}\right)\right)}\right)+ \\
& \frac{p_{r} q_{r}}{(n+2)^{2}}\left[\frac{1}{3}\left(q_{r}-p_{r}\right)\left(\frac{1+2\left(\Phi^{-1}\left(p_{r}\right)\right)^{2}}{\phi^{3}\left(\Phi^{-1}\left(p_{r}\right)\right)}\right)+\frac{1}{8} q_{r} p_{r}\left(\frac{\Phi^{-1}\left(p_{r}\right)\left(7+6\left(\Phi^{-1}\left(p_{r}\right)\right)^{2}\right)}{\phi^{3}\left(\Phi^{-1}\left(p_{r}\right)\right)}\right)\right]
\end{aligned}
$$

where $\Phi^{-1}(\cdot)$ and $\phi(\cdot)$ are the inverse CDF and PDF of the standard normal distribution respectively (David 1981). Moreover, from the familiar standardizing relation for normal random variables, the expected talent for officers drawn from any $N(\mu, \sigma)$ parent distribution is immediately obtainable via $X=\sigma Z+\mu$, where $Z$ represents the approximation for $E\left[X_{r: n}\right]$ given in (2). 
Using the above, suppose we are interested in estimating the expected talent of the Army's least capable Colonel in YG86, recalling: (a) it accessed 5932 officers, (b) the assumed distribution of talent within this cohort is $N(50,13$ ), and (c) the Army promoted 533 (or 8.99\%) of these officers to Colonel. Assuming perfect promotion boards, the expected talent of the least capable Colonel is equivalent to the expected talent of the officer with 533rd highest talent. Setting $r=5932-533+1=5400$ and $n=5932$ we obtain: $p_{r}=0.91016, q_{r}=0.08984, \Phi^{-1}\left(p_{r}\right)=1.34176$, and $\phi\left(\Phi^{-1}\left(p_{r}\right)\right)=0$.. Substituting these results into (2) yields $E\left[X_{5400: 5932}\right]=1.3421$ and converting this back into the $N(50,13)$ parent, we find that the expected talent of the cohort's least capable Colonel is 67.4474 .

Of course, as an approximate mathematical model a natural question arises: "Is this result reasonable?" In order to address this, we can simply compare the result with the estimate obtained from 1000 Monte Carlo trials, which produces an average talent of 67.4379 for the Colonel with the 533rd highest talent. While the obvious closeness of this result to the approximation provides good first glance verification, it is also worth noting that the result falls well within the $95 \%$ confidence interval for $\mu_{5400: 5932}$, namely $(67.4198,67.4559)$. Finally, the improvement in computational efficiency cannot be overstated. Specifically, using the Excel add-in XLSim the 1000 Monte Carlo trials took approximately 15 minutes to execute on an Intel ${ }^{\circledR} \mathrm{Core}^{\mathrm{TM}} 2 \mathrm{~T} 7600$ at $2.33 \mathrm{GHz}$ with $3.25 \mathrm{~GB}$ of RAM, while the approximation was calculated almost instantaneously. In short, under the assumptions discussed earlier, the above methodology provides a way to quickly and accurately assess the expected talent of any officer within a given cohort; the result is verified.

While quickly approximating the $r^{\text {th }}$ highest officer talent in the no-attrition model allows us to examine the minimum, median, and maximum officer talents at any rank, we might also be concerned with estimating the mean officer talent. Again, under the assumptions of perfect promotion and no attrition, this amounts to approximating the trimmed mean of the sample, where the officers below the promotion cut-line are removed from the sample and the remaining officer talents are averaged (Note: It is worth noting that the trimmed mean is different than the mean of a truncated distribution, as the latter implies restricting the domain of the original population).

With this in mind, the linearity of expectations states $\sum_{i=1}^{n} E\left[X_{i}\right]=E\left[\sum_{i=1}^{n} X_{i}\right]$, and this result holds regardless of the dependence or continuity of the $X_{i}$ provided $n$ is finite (Hogg 2005). Accordingly, we can simply sum the expected talents generated by (2) for each officer in a given grade and divide the result by the number of officers in the grade. Symbolically, this trimmed mean is given by:

$$
E\left[X_{j}\right]=\frac{\sum_{i=r_{j}}^{r_{j}+n_{j}-1} E\left[X_{i: n}\right]}{n_{j}}
$$

where $j$ is the grade, $r_{j}$ is the rank of the least talented officer in the grade, and $n_{j}$ is the number of officers within the grade. Although (3) provides a way to approximate $E\left[X_{j}\right]$, it requires the estimation of $n_{j}$ $E\left[X_{i: n}\right]$ s. Fortunately, a more compact result can be found in the area of selection differentials.

The selection differential $(D(k, n))$ of a random sample of $n$ observations captures the difference between the sample's average and the average of its $k$ largest observations (Burrows 1972). That is,

$$
D(k, n)=\frac{1}{k} \sum_{i=n-k+1}^{n} X_{i: n}-\frac{1}{n} \sum_{i=1}^{n} X_{i}
$$

Moreover, if the random sample is drawn from a standard normal population, then the expected value of (4) can be approximated by the relation: 


$$
E[D(k, n)]=\frac{\phi\left(\Phi^{-1}(1-k / n)\right)}{k / n}-\frac{n-k}{2 k(n+1) \frac{\phi\left(\Phi^{-1}(1-k / n)\right)}{k / n}}
$$

where $\Phi^{-1}(\cdot)$ and $\phi(\cdot)$ are the inverse CDF and PDF of the standard normal distribution respectively (Burrows 1972). Using YG86 as an example with $k=533$ and $n=5932$, (5) immediately yields 73.4602 for the mean talent of its Colonels, which compares very favorably with the $95 \%$ confidence interval $(73.4337,73.4753)$ for $E[D(533,5932)]$ obtained after 1000 Monte Carlo trials.

\section{REFERENCES}

Ahsanullah, M., \& Nevzorov, V.B. 2005. Order statistics: examples and exercises. Nova Publishers. Burrows, P.M. 1972. Expected Selection Differentials for Directional Selection. Biometrics 28:10911100.

David, H.A. 1981. Order Statistics. John Wiley \& Sons, Inc.

Hogg, R.V. 2005. Introduction to Mathematical Statistics. 6th ed. Pearson Prentice Hall.

Nadarajah, S. 2008. Explicit expressions for moments of order statistics. Statistics \& Probability Letters 78:196-205.

O'Keefe, B. 2010. Meet the New Face of Business Leadership. Fortune 161(4).

Wardynski, L., D.S. Lyle and M.J. Colarusso. 2010. Towards a U.S. Army Officer Corps Strategy, Talent: Implications for a U.S. Army Officer Corps Strategy. Strategic Studies Institute, U.S. Army War College, Volume 2.

\section{AUTHOR BIOGRAPHIES}

MATTHEW DABKOWSKI is an Assistant Professor in the Department of Systems Engineering at the United States Military Academy at West Point. He holds an M.S. in Systems Engineering from the University of Arizona and a B.S. is in Operations Research from the United States Military Academy. His research interests include multiple objective decision making, applied statistics, and simulation modeling. His email address is <matthew. dabkowski@us. army.mil>.

SAMUEL H. HUDDLESTON is an Analyst in the Operations Research Center of Excellence, United States Military Academy at West Point. He holds a Master of Science in Systems and Information Engineering from The University of Virginia and a Bachelors of Science from the United States Military Academy. His research interests include statistical learning, counter-terrorism, agent-based simulation and network analysis. His email address is <samuel. huddlestoneusma.edu>.

PAUL KUCIK is the Director of the Operations Research Center of Excellence, United States Military Academy at West Point. He holds a Ph.D. in Management Science and Engineering from Stanford University, an MBA from the Massachusetts Institute of Technology, and a B.S. in Economics from the United States Military Academy. His research interests include decision analysis, risk analysis, economics, counterinsurgency, and simulation modeling. His email address is <paul.kucik@usma.edu>.

DAVID LYLE is an Associate Professor of Economics and the Deputy Director of the Office of Economic and Manpower Analysis, United States Military Academy at West Point. He holds a Ph.D. in Economics from the Massachusetts Institute of Technology, and a B.S. in Economics from the United States Military Academy. His research interests include labor economics, human capital theory, peer effects, economics of national defense, and econometrics. His email address is <david. lyle@usma.edu>. 